\title{
Development of Centrifugation Straining Control System for Greek Yogurt Production Based on Weight of Whey Drain
}

\author{
Daniel Christianto \\ Master of Mechanical Engineering \\ Swiss German University \\ Tangerang City, Indonesia \\ danchrist94@gmail.com
}

\author{
1,2,* Cuk Supriyadi Ali Nandar \\ ${ }^{1}$ Master of Mechanical Engineering \\ Swiss German University \\ Tangerang City, Indonesia \\ ${ }^{2}$ Agency for the Assessment \& \\ Application of Technology (BPPT) \\ Tangerang, Indonesia \\ cuksupriyadi@gmail.com
}

\author{
Widi Setiawan \\ Master of Mechanical Engineering \\ Swiss German University \\ Tangerang City, Indonesia \\ widi_setia@yahoo.com
}

\begin{abstract}
Greek yogurt production needs a straining process that takes 10 hours or more. This paper proposes automation and control method for the centrifugation system to speed up the process time and to optimize the accuracy of quantity of whey drainage. Using system identification, the estimated mathematical model of straining process has been developed based on the traditional process of straining the yogurt. Then, the simulation and control design optimization has been carried out by using the estimated mathematical model. Based on the simulation results using whey mass controller, motor speed controller, and the combination of whey mass and motor speed controller, the controller that used are PID controller and fuzzy logic controller. The fastest controller is a PID controller as motor speed controller and fuzzy logic controller as whey mass controller that can speed up the production time and optimize the accuracy of quantity of whey drainage.
\end{abstract}

Keywords-greek yogurt, centrifugation, estimated model, control system, optimization

\section{INTRODUCTION}

In the world, yogurt has a very good position of consumer acceptance and growth. The popularity has increased due to the health benefits of yogurt. As a dairy product, yogurt is made from fermented milk. Milk contains six major nutrients: water, proteins, fat, carbohydrates, minerals, and vitamins. Water content in the milk varies from $85.4 \%$ to $87.7 \%$ depends on the species of cows. Some of water is bounded with the proteins. The major proteins in the milk are caseins and whey proteins [1].

One of yogurt type is strained yogurt, also known as Greek-style yogurt. This type of yogurt is concentrated by straining overnight using cloth bags after fermentation. The result is yogurt with high viscosity because of the drainage of whey. The whey drainage time can be 24-48 hours because of waiting the whey is drained from the yogurt [1] [3]. The process of straining yogurt shown in Fig. 1 .

With the high demand in the market and the slow process of straining the Greek yogurt, peoples try to solved the problems with hydrocolloids to hold water [4], ultrafiltered [2], and centrifugation [3]. Using 5 minutes centrifugation process, organoleptically the yogurt was similar to the control, traditional straining process [5]. Now the consumers demand natural yogurt, which is without addition like hydrocolloids [4] make the centrifugation method is more suitable to meets consumers' expectation.

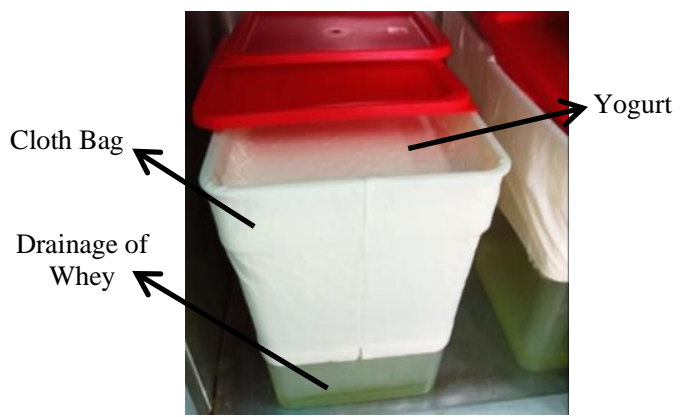

Fig. 1. Traditional straining process of Greek yogurt

In the straining process, the total liquid in the yogurt will decrease due to the drainage of whey. Moisture content of yogurt related to the yogurt viscosity and texture characteristic [1]. Controlling the quantity of drainage of whey can make the viscosity and texture of Greek yogurt still according to standards, that's means will maintain the quality.

To optimize the yogurt production process and to maintain product's quality, this paper proposes simulation of the centrifugation straining system using a PID and fuzzy logic controller to speed up the Greek yogurt production process. On the other hand, this research also optimizes the accuracy the drainage of whey quantity of the drainage of whey quantity in centrifugation straining system simulation. 


\section{GReeK Yogurt PRoduction Process}

In general, yogurt production process has same base ingredients and principles. The base ingredients are milk and yogurt starter culture. The starter culture is microorganisms that used to ferment the milk to become yogurt [1]. The general schematic of yogurt flow production is shown in Fig. 2.

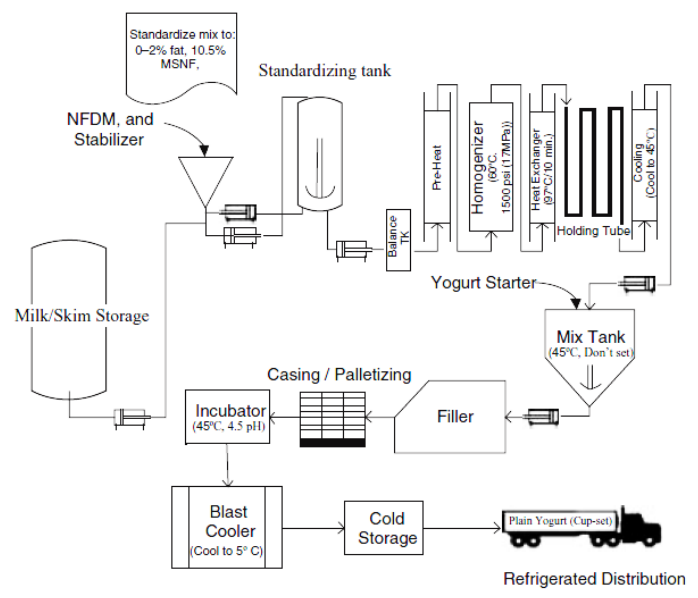

Fig. 2. Schematic general flow production of yogurt [1]

For the Greek yogurt, there is an additional process after the fermentation namely straining. Straining process is to drain the whey water using cloth bag $24-48$ hours at $4{ }^{\circ} \mathrm{C}$. Because of this process, total solids content in the yogurt increase from $14 \%$ to $21-23 \%$. It makes thick viscous body and fat content rises to approximately $10 \%$ [1-2]. This method requires a long time to produce certainly undesirable for large-scale production. Greek yogurt commercial manufacture relies on other processes than bag/gravity straining method. These processes are membrane filtration and centrifugation. Centrifugation straining process is adapted from soft-cheese manufacture. The yogurt is concentrated by using centrifuge system. The system will separated yogurt into curd and whey by using centrifugal force [2].

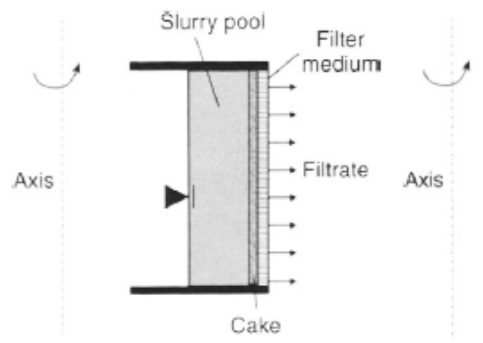

(a)

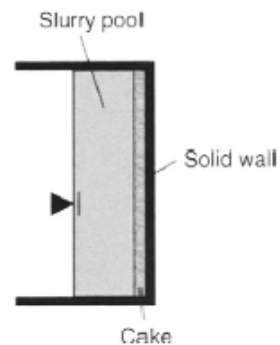

(b)
Fig. 3.Schematic of (a) filtering and (b) sedimenting centrifugal separator [6]

Centrifugal separator can be divided into two classes: filtering and sedimenting (Fig. 3). In filtering method, solid phase and liquid phase are driven under the centrifugal force to the perforated filter medium. The liquid phase permeates through the filter medium and the solid phase is restrained by the filter medium. Sedimenting centrifugal separator has a solid wall, the material will centrifuge under centrifugal acceleration. The separation process caused by difference of density between the solid and liquid phase [6].

When a constant centrifugal force is applied to the yogurt, the whey will stop draining from yogurt depends on the force. In Fig. 4, 10\% total solid yogurt applied force $1086 \mathrm{~g}$ and $482 \mathrm{~g}$, the volume of drainage whey will reach a constant value. The centrifugal force is very important to optimize the process. So that centrifugal force controller design is highly needed. Fig. 5 shows the relationship between percentage of whey and centrifugal force [7].

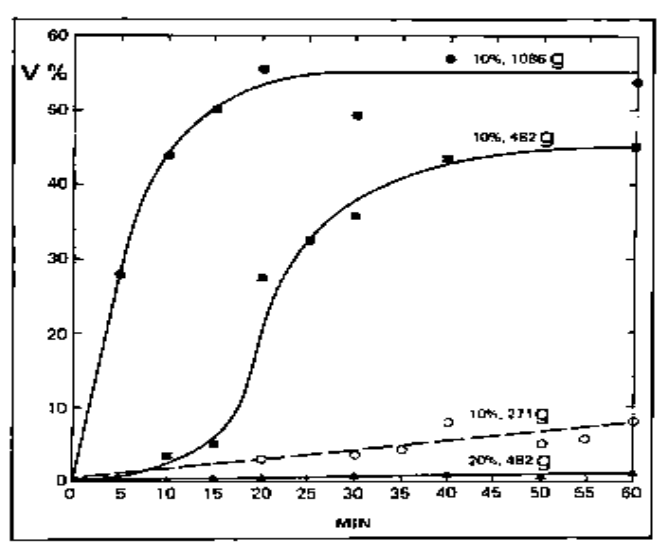

Fig. 4. Separation of whey from yogurt with constant centrifugal force [7]

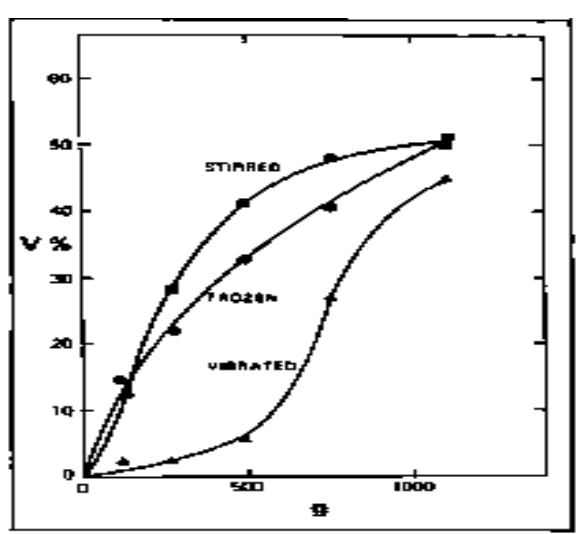

Fig. 5.Centrifugation profiles of yogurt [7]

\section{CONTROL SYSTEM DESIGN}

The control system is a system that some or all inputs are used to control the outputs to some particular value [8]. Main control system components are control objectives, control system components, and results as shown in Fig. 6. The objectives can be mentioned as inputs or actuating signals, and the result can be called as output or controller variables [9].

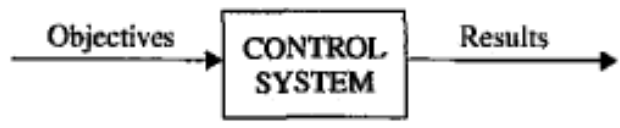

Fig. 6.Main components of control system [9]

Two types of control system are open loop control system (non-feedback) and close loop control system (feedback). Schematic diagrams of open loop control 
system and closed loop system are shown in Fig. 7 and Fig. 8 respectively [8]. Because of open loop control system is simple and economic, many noncritical applications recommend to use this controller. However, the accuracy of open loop control is weak. Therefore, close loop system is developed to get more accurate and more adaptive [9].

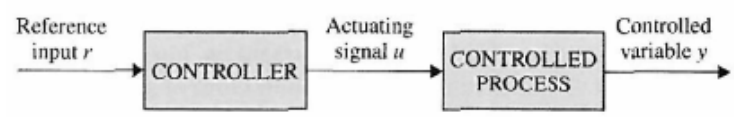

Fig. 7.Open loop control system block diagram [9]

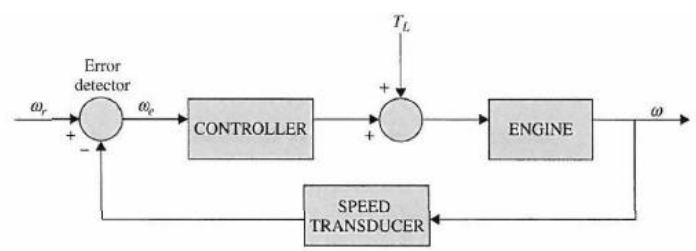

Fig. 8. Close loop control system block diagram [9]

\section{A. PID Controller}

PID controller is a combination of three modes of control, proportional, integral, and derivative controller. There are two methods of PID controller tuning that widely used, process reaction method and the ultimate cycle method by Ziegler and Nichols [8].

In this paper, Ziegler and Nichols tuning method is applied. The first method of Ziegler and Nichols tuning method use the equation as follows:

$G_{C}(s)=1.2 \frac{T}{L}\left(1+\frac{1}{2 L s}+0.5 L s\right)$

Where the variable $\mathrm{T}$ and $\mathrm{L}$ are given from step response as shown in Fig. 9.

The second tuning method is shown in the following equation:

$G_{C}(s)=0.075 K_{c r} P_{c r} \frac{\left(s+\frac{4}{P_{c r}}\right)^{2}}{s}$

Where $P_{c r}$ is critical period of sustained oscillation as shown in Fig. 10.

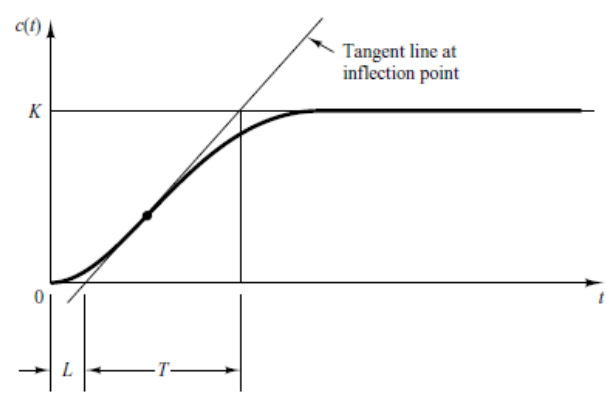

Fig. 9. S-shaped curve response to a step input [10]

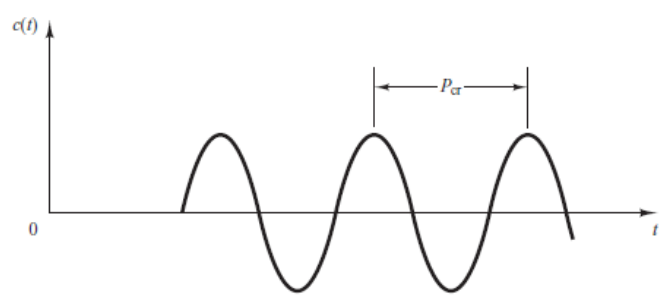

Fig. 10. Sustained oscillation [10]

\section{B. Fuzzy Logic Controller}

Fuzzy logic is using principles and methods of human logic reasoning [11] and observation [12]. The Fuzzy logic scheme is depicted in Fig. 11 [13], where fuzzy logic receives imprecise data and vague statements such as low, medium, and high to provide a decision, shown in Fig. 11 [13].

Fuzzy logic controller consist of fuzzification, fuzzy logic rule base, and defuzzification. Fuzzification is transform the physical values from the process signal becomes an interval for the range of input values, that called membership functions (Fig. 12). The fuzzy logic rule base is developed by the if-then rules from the input membership function to the output membership function. Defuzzification process is to convert the fuzzy terms created by the rule base to a numerical values [11].

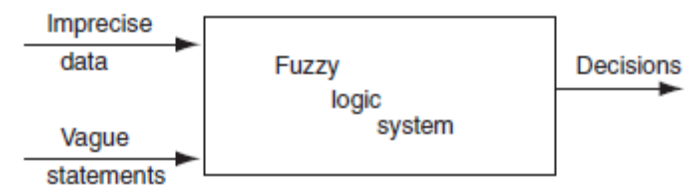

Fig. 11.Fuzzy logic system [12]

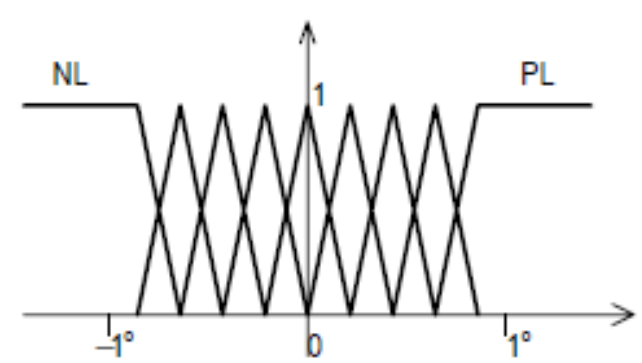

Fig. 12. Examples of membership functions [11]

\section{SimUlation Results}

\section{A. System Identification}

In this study, system modelling of straining process for Greek yogurt using some components such as Load cell as a sensor to measure the weight of drainage whey, HX711 as a load cell module for Arduino, Infrared Speed Sensor for measure the speed of the motor, Arduino MEGA as a controller, Single Phase Inverter for set the speed of motor, and $\mathrm{AC}$ motor as a actuator to rotate the Greek yogurt. The diameter of the drum in this design for simulation is $20 \mathrm{~cm}$.

For system identification, the data will collected from the traditional method of straining process for Greek yogurt 
by measuring the weight of whey drained by the time. The mass of whey drainage data is taken every 30 minutes during the Greek yogurt production with an initial mass of the yogurt is $4.96 \mathrm{~kg}$, and the mass of whey drainage data graphs is shown in Fig. 13. Based on MATLAB system identification results in Fig. 14, the best system identification result is $99.53 \%$ (9 poles and 8 zeros).

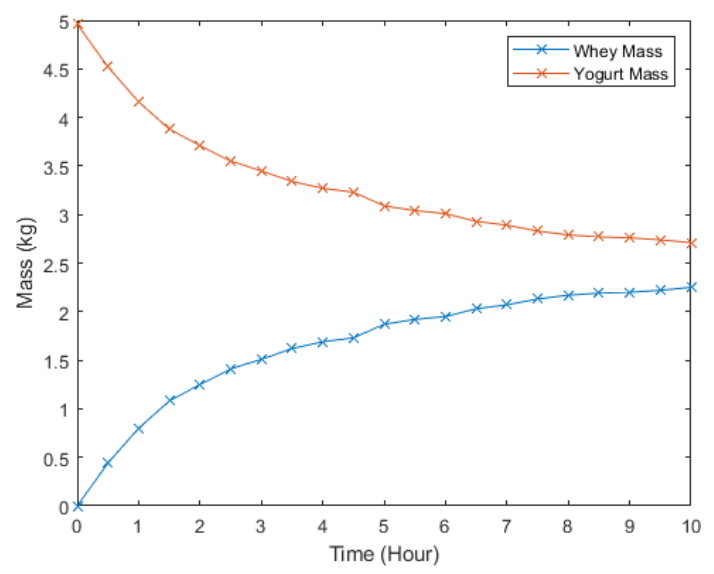

Fig. 13. Whey mass vs time and yogurt mass vs time

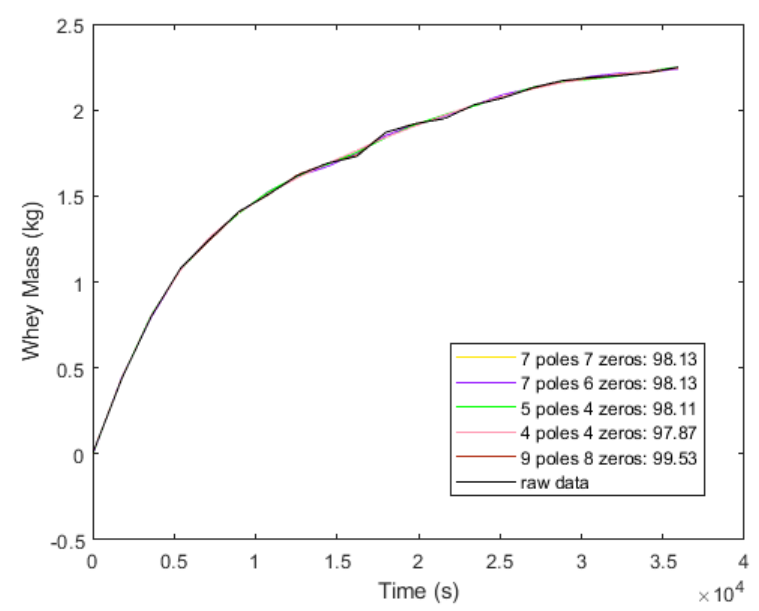

Fig. 14. Measured and simulated model output

\section{B. Simulation results}

Simulation studies are carried out using Simulink model. The system response without controller is shown in Fig. 15. The system has been stopped in $68.79 \mathrm{~s}$ with a weight deviation about $19 \mathrm{~g}$ (lower than a target).

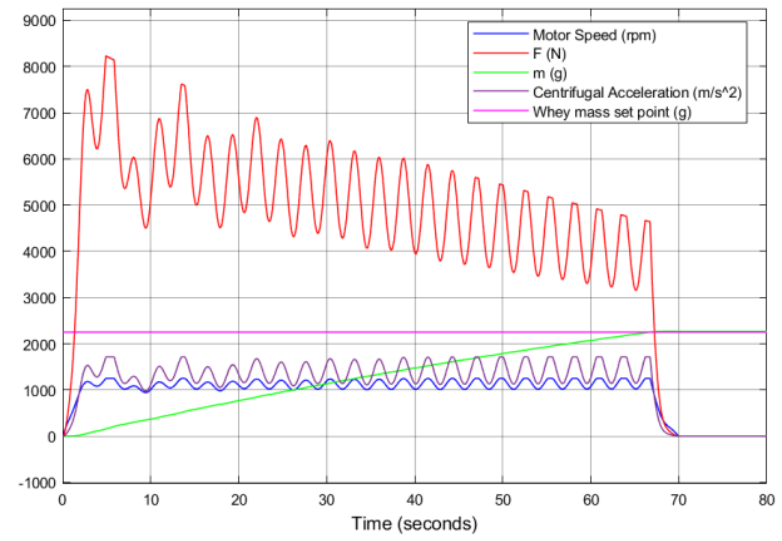

Fig. 15. Response from the centrifugation system

To improve the system response and reduce the deviation, three kind simulation has been applied. There are whey mass control system (Fig. 16), motor speed control system (Fig. 17), and whey mass and motor speed control system (Fig. 18). On the other hand, PID controller and fuzzy logic controller will be compared. The response results of all simulation scenarios are shown in Table I.

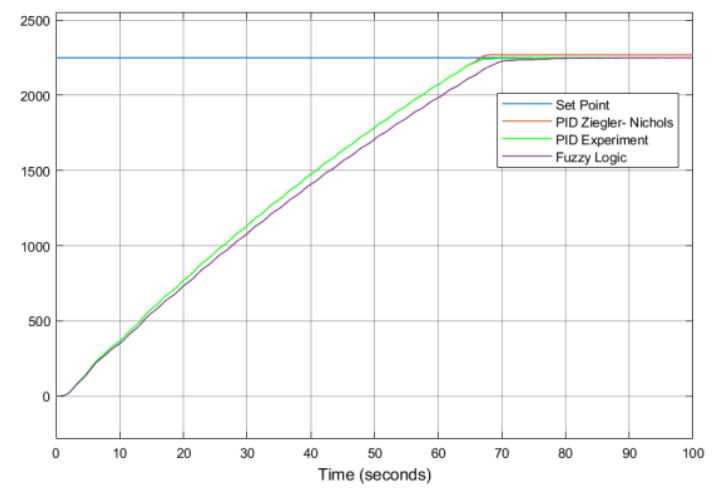

Fig. 16. System response with whey mass controller

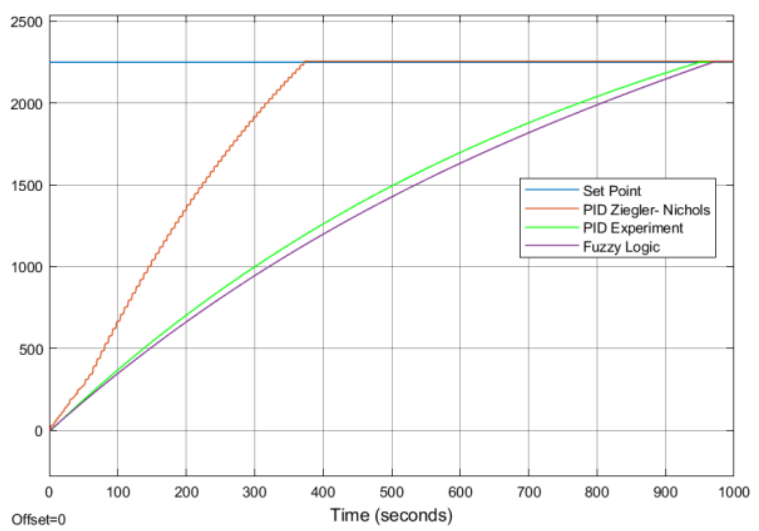

Fig. 17. System response with motor speed controller 


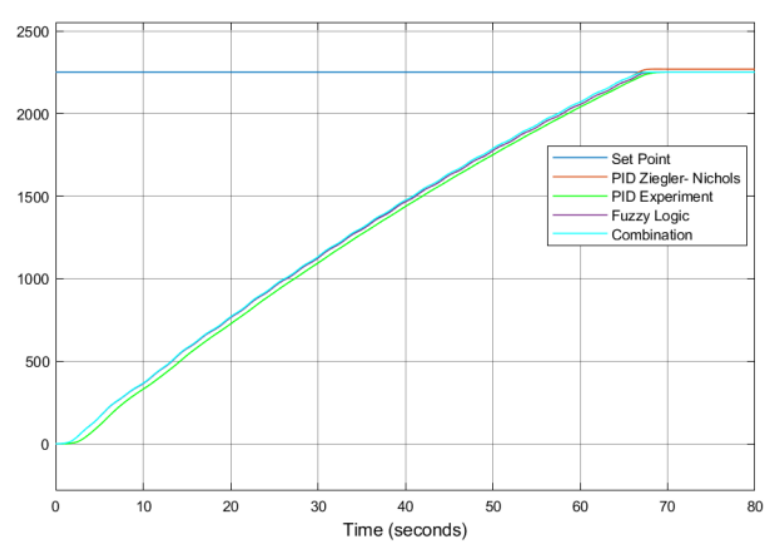

Fig. 18. System response with motor speed and whey mass controller
Based on the simulation results, the best response result is the combination between PID controller as motor speed controller and fuzzy logic controller as whey mass controller that can reach the set point in 67.809 seconds.

The proposed controller method can improve the process time in comparison with the traditional method that needs 10 hours. In traditional way, the timing of the straining process depends on the quantity of total solid in the Greek yogurt, but usually it can take 24-48 hours [1] and using 5 minute centrifugation process, organoleptically the yogurt was similar to the traditional straining process [5]. In this study, the timing of the traditional straining process is 10 hours, follow the standard from the factory that the data is collected. And after using control system centrifugation in simulation the timing of straining process is reduced to 67.809 seconds. From $24-48$ hours to 5 minutes, the time reduced 288-576 times and from 10 hours to 67.809 seconds, the time is reduced 531 times.

TABLE I

SYSTEM RESPONSE SIMULATION RESULT

\begin{tabular}{ccc}
\hline Description & Result & Time (s) \\
\hline PID Ziegler-Nicols whey mass & Exceed the set point & 68.720 \\
PID experiment whey mass & Reach the set point & 75.763 \\
Fuzzy whey mass & Reach the set point & 94.984 \\
PID Ziegler-Nichols motor speed & Exceed the set point & 372.808 \\
PID experiment motor speed & Reach the set point & 950.605 \\
Fuzzy motor speed & Reach the set point & 969.843 \\
PID Ziegler_Nichols combination & Reach the set point & 68.791 \\
PID experiment combination & Reach the set point & 70.377 \\
Fuzzy combination & Reach the set point & 69.432 \\
PID motor speed and fuzzy whey mass & Reach the set point & 67.809
\end{tabular}

\section{CONCLUSIONS}

Automation and control method for the centrifugation system to speed up the process time and to optimize the accuracy of quantity of whey drainage has been proposed in this study. The estimated mathematical model of straining process has been developed by using system identification. Simulation studies have been carried out using Simulink/Matlab with various controllers, there are whey mass controller, motor speed controller, and combinations of whey mass and motor speed controller. PID controller and fuzzy logic controller are applied to the system. Based on the simulation results, the best controller is a PID controller as motor speed controller and fuzzy logic controller as whey mass controller. The combination of both type controllers is most accurate to control the quantity of drainage of whey with the process time only needs 67.809 seconds. The results show that the proposed controller is able to speed up the process time for straining Greek yogurt about 10 hours using traditional method and 5 minutes using the previous method with high quality of products.

\section{ACKNOWLEDGMENT}

The author would like to express his sincere gratitude to Dr. Cuk Supriyadi Ali Nandar, S.T., M.Eng and Dr. Ir. Widi Setiawan, lecturers in Master of Mechanical Engineering at Swiss German University for their collaboration in this work.

\section{REFERENCES}

[1] C. H. White, A. Kilara, and Y. H. Hui, Manufacturing Yogurt and Fermented Milks. Oxford: Blackwell, 2006.

[2] R. C. Chandan and A. Kilara, Manufacturing Yogurt and Fermented Milks, 2nd ed. John Wiley \& Sons, Inc, 2013.

[3] C. E. Jørgensen, R. K. Abrahamsen, E. O. Rukke, T. K. Hoffmann, A. G. Johansen, and S. B. Skeie, "Processing of high-protein yoghurt - A review," Int. Dairy J., 88, pp. 42-59, 2019.

[4] R. Gyawali and S. A. Ibrahim, "Effects of hydrocolloids and processing conditions on acid whey production with reference to Greek yogurt,” Trends Food Sci. Technol., 56, pp. 61-76, 2016.

[5] B. Y. A. Y. Tamime and R. K. Robinsonf, "Fermented milks and their future trends. Part II. Technological aspects," J. Dairy Res., 55, pp. 281-307, 1988.

[6] W. W. F. Leung, Centrifugal Separation in Biotechnology, vol. 2. Oxford: Elsevier, 2007. 
[7] V. R. Harwalkar and M. Kalab, "Susceptibility of yoghurt to syneresis. Comparison of centrifugation and drainage methods," Milchwissenschaft, 1983.

[8] W. Bolton, Instrumetation and Control Systems, no. August. Elseview Science \& Technology Books, 2004.

[9] F. Golnaraghi and B. C. Kuo, Automatic Control Systems, 9th ed. United States of America: John Wiley \& sons, Inc, 2010.

[10] K. Ogata, Modern Control Engineering, 5th ed. New Jersey: Prentice Hall, 2010.
[11] G. Chen and T. T. Pham, Introduction to Fuzzy Sets, Fuzzy Logic, and Fuzzy Control System. Florida: CRC Press LLC, 2001.

[12] F. Wijaya, "Design of fuzzy logic controller for charging system with temperature condition system in excavator," 1st Proceedings of The Conference on Management and Engineering in Industry (CMEI 2019)," vol. 1, pp. 27-30, Tangerang, Indonesia, August 2019.

[13] S. N. Sivanandam, S. Sumathi, and S. N. Deepa, Introduction to fuzzy logic using MATLAB. New York: Springer, 2007. 